\title{
Chloride Transport in OPC Concrete Subjected to the Freeze and Thaw Damage
}

\author{
Ki Yong Ann, ${ }^{1}$ Min Jae Kim, ${ }^{1}$ Jun Pil Hwang, ${ }^{1}$ Chang-geun Cho, ${ }^{2}$ and Ki Hwan Kim ${ }^{1}$ \\ ${ }^{1}$ Department of Civil and Environmental Engineering, Hanyang University, Ansan 15588, Republic of Korea \\ ${ }^{2}$ School of Architecture, Chosun University, Gwangju 61452, Republic of Korea \\ Correspondence should be addressed to Ki Yong Ann; kann@hanyang.ac.kr
}

Received 7 October 2016; Revised 21 December 2016; Accepted 26 January 2017; Published 16 February 2017

Academic Editor: Rishi Gupta

Copyright (c) $2017 \mathrm{Ki}$ Yong Ann et al. This is an open access article distributed under the Creative Commons Attribution License, which permits unrestricted use, distribution, and reproduction in any medium, provided the original work is properly cited.

\begin{abstract}
To predict the durability of a concrete structure under the coupling degradation consisting of the frosting and chloride attack, microstructural analysis of the concrete pore structure should be accompanied. In this study, the correlation between the pore structure and chloride migration for OPC concrete was evaluated at the different cement content in the concrete mix accounting for 300,350 , and $400 \mathrm{~kg} / \mathrm{m}^{3}$ at 0.45 of a free water cement ratio. The influence of frosting damage on the rate of chloride transport was assessed by testing with concrete specimens subjected to a rapid freezing and thawing cyclic environment. As a result, it was found that chloride transport was accelerated by frost damage, which was more influential at the lower cement content. The microscopic examination of the pore structure showed that the freezing environment increased the volume of the large capillary pore in the concrete matrix.
\end{abstract}

\section{Introduction}

Concrete structures such as concrete pavements and concrete bridge decks in the cold climate often experience the deicer to mitigate the slipperiness of the pavement surface arising from snowing. Sodium chloride $(\mathrm{NaCl})$ salt and calcium chloride $\left(\mathrm{CaCl}_{2}\right)$ are the representative deicers, which however imposes a potential risk of chloride-induced corrosion of steel in the concrete structure. Steel embedment in concrete is usually protected from the risk of corrosion by a thin oxide layered film, the so-called " $\gamma-\mathrm{Fe}_{2} \mathrm{O}_{3}$ passive film" generated in the alkaline concrete pore solution [1]. Notwithstanding, chloride ions present in the concrete, pore solution may activate the electrochemical reaction then to corrode steel [2]. Once corrosion starts on the steel surface, the volume of the steel rebar expands about 3-8 times of the original volume [3], leading to a loss of the tensile capacity of steel and spalling of cover concrete, which substantially could bring a devastating failure of the structure. Despite the risk of steel corrosion, the deicing salt is an unavoidable manner to secure the traffic condition against snowing.
Moreover, the concrete pore structure may be damaged by freezing and thawing in the cold climate. Water confined in the pore system of cement matrix, when freezing, exposes the pore walls to stresses, which might cause intense damage to the structure. In particular, in the presence of the deicing salt, the destruction of the pore structure can be accelerated. Ice bodies, which have already been formed in coarser pores, are able to attract unfrozen water from finer capillary pores and gel pores, due to the difference in free energy between ice and water [4]. Then, there would be a water transfer to the freezing site, thereby a growth of the ice body in the pores and a breakdown of cement paste surrounding the pore system (i.e., a generation of microcracking). Substantially, the frost damage may provide a better path for chloride ions to reach at the depth of the steel in concrete, as being associated with further corrosion process and thus the severer deterioration of the concrete structure may occur. However, the combined deterioration, especially about a degradation of physical property and accelerated chloride penetration induced by frost damage, has not been fully clarified. 
TABLE 1: Oxide composition of use material.

\begin{tabular}{lcccccccc}
\hline \multirow{2}{*}{ Binder type } & \multicolumn{9}{c}{ Oxide compositions (\%) } \\
& $\mathrm{CaO}$ & $\mathrm{SiO}_{2}$ & $\mathrm{Al}_{2} \mathrm{O}_{3}$ & $\mathrm{Fe}_{2} \mathrm{O}_{3}$ & $\mathrm{MgO}$ & $\mathrm{Na}_{2} \mathrm{O}$ & $\mathrm{K}_{2} \mathrm{O}$ & $\mathrm{SO}_{3}$ \\
\hline OPC & 64.7 & 20.7 & 4.6 & 3.0 & 1.0 & 0.13 & 0.65 \\
\hline
\end{tabular}

In this reason, the present study is concerned about the combined effect of the two deteriorations (i.e., chloride attack and frost damage) by measuring relative dynamic modulus of elasticity and the degree of chloride transport. Moreover, microstructure analysis was also conducted to verify the change of pore system during repetitive freezing and thawing condition.

\section{Experimental Work}

Concrete specimens were fabricated in a cylindrical $(\varnothing 100 \mathrm{~mm} \times 200 \mathrm{~mm})$ and cuboidal $(100 \times 100 \times 400 \mathrm{~mm})$ mould for chloride migration test and relative dynamic modulus of elasticity test, respectively. The specific gravity of the fine aggregate was 2.60 and coarse aggregate was 2.65. The maximum size of the coarse aggregate used in a concrete mix was always $10 \mathrm{~mm}$ to minimize the disruption of ionic transport. The ratio of the fine aggregate to total was 0.4 for all mixes. Ordinary Portland cement (OPC) was used for a binder and its oxide composition is given in Table 1.

The binder content was ranged from 300, 350 and $400 \mathrm{~kg} / \mathrm{m}^{3}$. The freezing and thawing test specimens generally manufactured by less than 0.35 of water-cement ratio. However, since the purpose of this study is to observe the combined deterioration induced by frost damage and chloride attack, the water-cement ratio was kept at 0.45 for all cases. Moreover, no chemical admixture such as air entrainer was used to avoid unexpected chemical reaction which can influence the test result. All concrete specimens were demoulded 24 hours after casting and cured in a chamber with $95 \% \mathrm{RH}$ at $20 \pm 2^{\circ} \mathrm{C}$ for 500 days of which hydration effect become negligible during the test. After curing, the concrete specimens were directly subjected to the freezethaw condition, followed by tests for chloride migration and microscopic investigation. For all tests, the replications were always five to cover the variation in the values. The details of each test procedure are given in the following.

2.1. Testing for Frost Damage. To emulate the frost damage on concrete, the concrete specimens were exposed to a cyclic freeze and thaw environment. The concrete specimens after 500 days of curing were allowed to rapidly freeze in the atmospheric condition and then to thaw in water in an insulting chamber. The temperature variation in the chamber ranged from 5 to $-18^{\circ} \mathrm{C}$. For the freezing period, the temperature of the chamber was kept at $-18^{\circ} \mathrm{C}$ for 1.5 hours and then still water was supplied to thaw the specimens by increasing the temperature back to $5^{\circ} \mathrm{C}$ within $5.0 \mathrm{~h}$. The freezing and thawing rate were kept at $10^{\circ} \mathrm{C} / \mathrm{h}$. The cyclic freeze and thaw were repeated up to 60,120 , and 180 cycles. The details of testing procedure are given elsewhere [5].
The relative dynamic modulus of elasticity of concrete specimens was measured to detect internal degradation by applying ultrasonic pulse. The test was conducted at 60, 120, and 180 cycles of freeze and thaw, accompanied with chloride migration test and MIP.

2.2. Testing for Chloride Migration. Cylindrical concrete specimens sawed off to produce a disc sample with $50 \mathrm{~mm}$ in the thickness, after the completion of curing for 500 days. The specimen was connected to two chambers filled with $10.0 \%$ $\mathrm{NaCl}$ and with $0.3 \mathrm{M}$ sodium hydroxide $(\mathrm{NaOH})$ solutions, respectively, to form an electric cell. A direct current at $30 \mathrm{~V}$ was applied to the cell for 30 hours.

After applying the current, the specimens were axially split into two pieces and $0.1 \mathrm{M}$ silver nitrate $\left(\mathrm{AgNO}_{3}\right)$ solution was sprayed on the surface of the split section to form the visible precipitation of silver chloride $(\mathrm{AgCl})$. The depth of the precipitation of silver chloride was measured by a ruler four times and then the average value was chosen as the chloride penetration depth. Then, the migration coefficient was calculated by (1), derived by the Nernst-Plank equation. The detailed procedure for measuring the chloride migration coefficient is given elsewhere [6].

$$
\begin{gathered}
D_{\text {mig }}=\frac{0.0239(273+T) L}{(U-2) t}\left\{X_{d}\right. \\
\left.-0.0238 \sqrt{\frac{(273+T) L X_{d}}{U-2}}\right\},
\end{gathered}
$$

where $D_{\text {mig }}$ is migration coefficient, $\times 10^{-12} \mathrm{~m}^{2} / \mathrm{s} ; U$ is applied voltage, $\mathrm{V} ; \mathrm{T}$ is temperature of the cell, ${ }^{\circ} \mathrm{C} ; L$ is thickness of the specimen, $\mathrm{mm} ; X_{d}$ is chloride penetration depth, $\mathrm{mm} ; t$ is test duration, hour.

2.3. Testing for Microscopic Examination. Deformation of pore structure after severe freeze-thaw environment was examined using mortar sample, not to reflect the distortion effect of coarse aggregate. The mortar samples, after 500 days of curing, were crushed to obtain the middle of specimen, which may form a homogeneous pore matrix. Then, the sample was dried out in an oven at $50^{\circ} \mathrm{C}$ for 7 days to liberate water content inside of the material that might otherwise give undesired test result. The sample was initially evacuated to about $50 \mu \mathrm{m}$ mercury $(\mathrm{Hg})$ and the low pressure was generated up to $0.21 \mathrm{MPa}$ by nitrogen gas, and then the pressure was gradually increased to $117.21 \times 10^{3} \mathrm{MPa}$ at the rate of $9.1 \times 10^{3} \mathrm{kPa} / \mathrm{s}$. The pressure was converted to the 


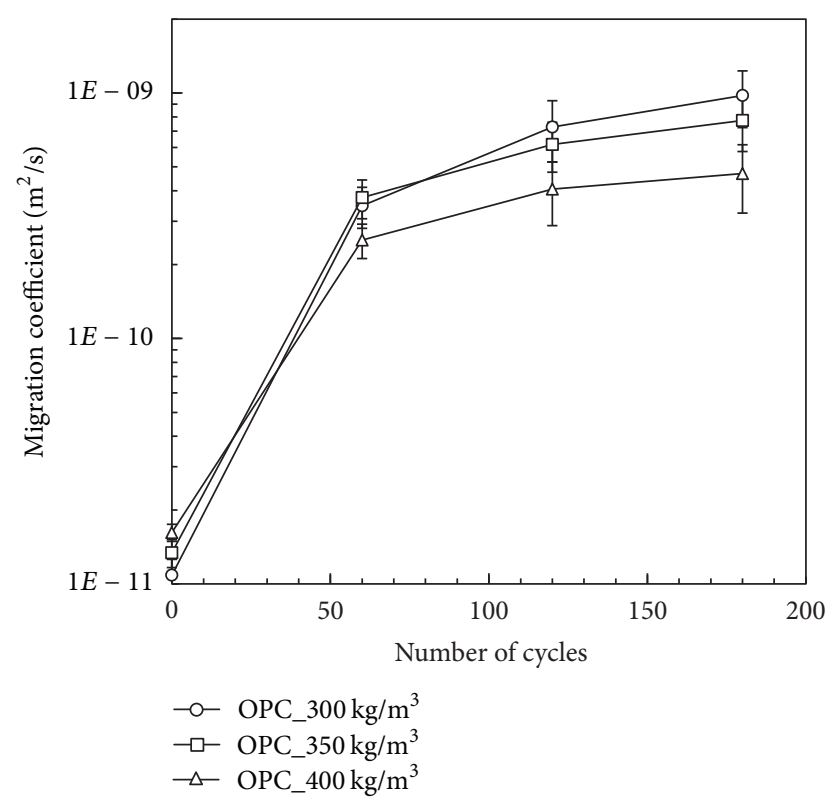

FIGURE 1: Migration coefficient for concrete after frosting depending on binder content.

equivalent pore diameter using the Washburn equation as given in (2). Then the pore volume distribution at a given pore diameter was obtained. The pore volume was adjusted to the percentage of the volume of each sample.

$$
d=\frac{-4 \gamma \cos \theta}{P}
$$

where $d$ is pore diameter, $\mathrm{m} ; \gamma$ is surface tension, $\mathrm{N} ; \theta$ is contact angle, ${ }^{\circ} ; P$ is pressure, $\mathrm{MPa}$.

\section{Result and Discussion}

3.1. Frost Damage. After an exposure of concrete specimens to different cyclic durations for freeze and thaw (i.e., 0,60 , 120 and 180 cycles), the migration coefficient of chloride ions of the specimens was calculated by (1), as given in Figure 1. The initial migration coefficient for 300,350 , and $400 \mathrm{~kg}$ of cement content was $0.109 \times 10^{-10}, 0.134 \times 10^{-10}$, and 0.162 $\times 10^{-10} \mathrm{~m}^{2} / \mathrm{s}$, respectively, before being subjected to a freeze and thaw cyclic environment. The migration coefficients increased with the number of cycles, irrespective of cement content. This implies that the pore structure was presumed to turn more porous in the process of freeze and thaw, due to the internal pressure generated by ice formation in the pore solution, which could, in fact, enhance the connectivity between capillary pores including even isolated pores. Thus, continuous pore fractions can be used for chloride ions to increase the mobility through the pores. Furthermore, a reduction of the concrete surface in the process of freeze and thaw could produce further porosities, in terms of cracking of cover concrete, which provides additional paths for chloride transport. It is notable that, at a high number of freeze and thaw cycles, the rate of chloride penetration was less increased. At the initial cycles, up to 60 , the migration coefficient was more rapidly increased, compared to longer exposure period, from 60 to 180 . For example, the migration coefficient for $300 \mathrm{~kg}$ of cement content was $3.47 \times 10^{-10} \mathrm{~m}^{2} / \mathrm{s}$ at 60 cycles and reached $9.77 \times 10^{-10} \mathrm{~m}^{2} / \mathrm{s}$ after 180 cycles. This may be attributed to limited deterioration of cover concrete arising from freeze and thaw cyclic conditions. An increase in the pore connectivity and cracking-originated pores may result from frost damage more or less, and however, after a certain level of deterioration, the pore structure may be stably sustained with no increase in the capillary pores. Then, ionic transport would be less influenced by the number of freeze and thaw cycles in a long term.

It is evident that increased cement content in the concrete mix was more resistant to chloride migration under frost damage. It was observed that an increase in the cement content resulted in a lower migration coefficient with cycles of freeze and thaw. In fact, there was a marginal variation in the migration coefficient with cement content at no exposure to freeze and thaw condition. Then, with increasing the cycles of freeze and thaw, the higher cement content in mix produced the lower migration coefficient. For example, at 180 cycles, the migration coefficient for 300,350 , and $400 \mathrm{~kg} / \mathrm{m}^{3}$ of cement accounted for $9.77 \times 10^{-10}, 7.73 \times 10^{-10}$, and $4.70 \times 10^{-10} \mathrm{~m}^{2} / \mathrm{s}$, respectively. It may reflect that the higher cement content may resist the frost damage. As a given free water cement ratio (0.45) was used in concrete mixes, no possibility of the variation in the pore structure could be achieved, as long as the pores are assumed to be produced in the cement matrix. However, the higher cement content, in turn, implies the lower aggregate content and thus lowers interfacial porosity between cement paste and aggregate, which is usually vulnerable to frost damage. Thus, the higher cement content in the concrete mix may be more resistant to frost damage in terms of increased porosities, in particular, connectivity between capillary pores.

This phenomenon can be confirmed by measuring the relative dynamic modulus of elasticity of concrete subjected to freeze and thaw cycles, as given in Figure 2. An increase in the cycle numbers of freeze and thaw resulted in a decrease in the relative dynamic modulus of elasticity, irrespective of cement content. However, concrete at the lower cement content produced a more rapid reduction of the relative dynamic modulus of elasticity at a given number of the freeze and thaw cycles. For example, for $300 \mathrm{~kg} / \mathrm{m}^{3}$ of cement content, the relative dynamic modulus of elasticity accounted for $88.29,72.32$, and $49.39 \%$ of elasticity at 60,120 , and 180 cycles, whilst $400 \mathrm{~kg} / \mathrm{m}^{3}$ produced $87.55,75.28$, and $58.59 \%$ at the equivalent cycles. Thus it can be said that the higher cement content may benefit in raising the resistance to frost damage at a given free water cement ratio, except for the use of air-entraining agents. Notwithstanding, all specimens did not maintain the minimum level for the relative dynamic modulus of elasticity to secure the safety of the structure, accounting for $60 \%$ at 300 cycles; in fact the relative dynamic modulus of elasticity was lower than $60 \%$ at 180 cycles due to the absence of air entraining agent and the higher watercement ratio rather than guided values. 


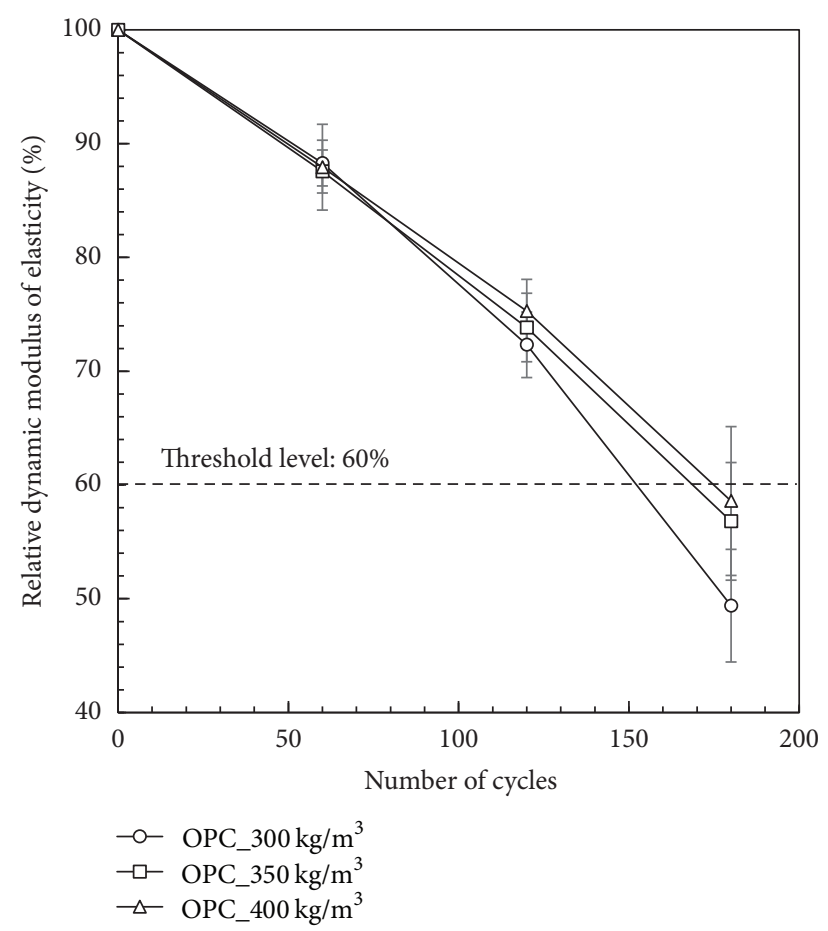

Figure 2: The relative dynamic modulus of elasticity under freezethaw condition.

3.2. Pore Structure Analysis. To ensure a modification of the porosity under freeze and thaw damage, the pore structure was examined by the mercury intrusion porosimetry (MIP). The total pore volume was obtained at each cycle and cement content as given in Figure 3. It is evident that cement content was crucial in increasing the total pore volume; the initial porosity was $11.91,14.60$, and $15.51 \mathrm{~mL} / \mathrm{g}$ for 300,350 , and $400 \mathrm{~kg} / \mathrm{m}^{3}$ of cement content, respectively. However, after 180 cycles of freezing and thawing, the total pore volume was changed to $18.04,18.61$, and 17.10 for 300,350 , and $400 \mathrm{~kg} / \mathrm{m}^{3}$ of cement content, respectively. This may be attributed to the resistance of porosity or/and air bubble to frost damage. In fact, increased porosity may buffer internal stress arising from freezing the pore solution in the pores and thus frost damage could be mitigated. The higher porosity may benefit in lowering breakage of pore network, resulting from freeze and thaw cycles. Additionally, it was observed that an increase in the porosity was observed at 60 cycles rather than subsequent cycles, at which there was no significant change in the total pore volume for 350 and $400 \mathrm{~kg} / \mathrm{m}^{3}$ of cement content and only marginal increase was observed for $300 \mathrm{~kg} / \mathrm{m}^{3}$ of cement content. It implies that the crack-induced porosity would be formed at an early stage of freeze and thaw cycles, which would buffer subsequent internal stress from freezing the pore solution and thus no further formation of cracking was formed.

The pore size distribution was used to determine modification of pore structure change after frost damage, as given Figure 4. The pore diameter of pore at the highest peak (i.e., critical diameter) was determined, and simultaneously, pores

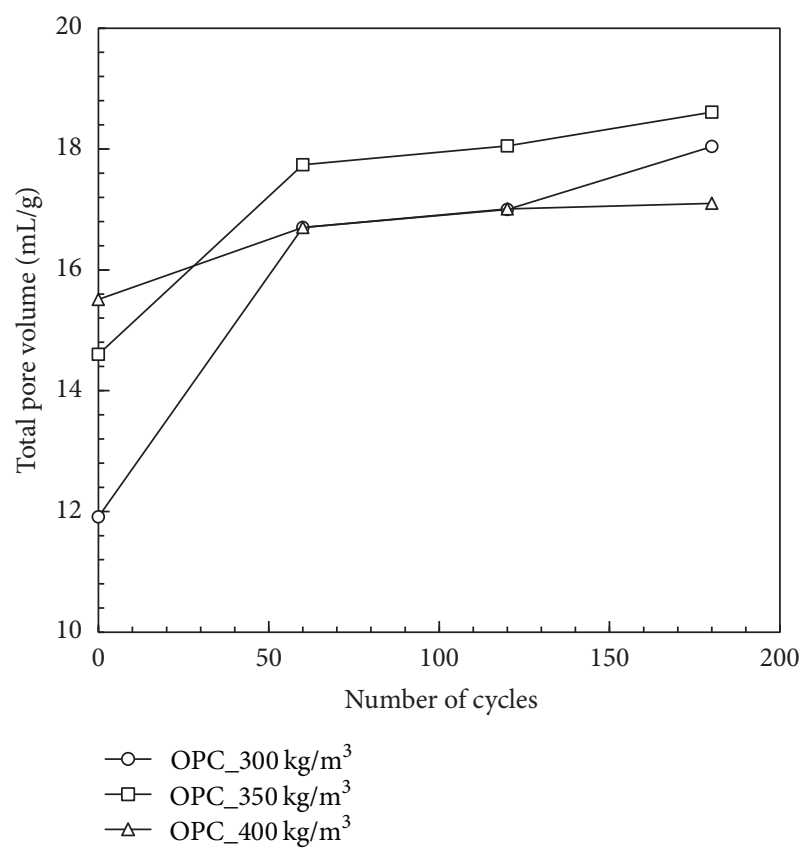

FIGURE 3: Total pore volume for 300,350 , and $400 \mathrm{~kg} / \mathrm{m}^{3}$ of cement content at $0,60,120$, and 180 cycles.

were classified by the size as small capillary $(d<0.1 \mu \mathrm{m})$, large capillary $(0.1<d<10 \mu \mathrm{m})$, and macropores $(d>10 \mu \mathrm{m})$. At 0 cycle, the peak of porosity was observed at about $0.5-$ $0.7 \mu \mathrm{m}$ in the diameter. It was seen that the pore volume was strongly dependent on large capillary pore, of which the volume accounted for 4.32,5.12, and $6.95 \mathrm{~mL} / \mathrm{g}$, respectively, and 300,350 , and $400 \mathrm{~kg} / \mathrm{m}^{3}$ of cement with no exposure to freeze and thaw cycles. With increasing cycles of freeze and thaw, the volume of large capillary pore was significantly increased, compared to other sizes of pores. This may be due to the fact that crack formed in the process of freeze and thaw would be equated to the large capillary pores in size. The other pores were also modified by the freeze and thaw. For example, the breakage of small capillary pore was reduced by suspended pressure in the pore network, which in turn gave relatively lower expansive force [7]. It is notable that freeze and thaw cycles were influencing critical pore diameter, which was, for example, 0.045, 0.072, 0.088, and $0.095 \mu \mathrm{m}$ at $0,60,120$, and 180 cycles of freeze and thaw, respectively, for $300 \mathrm{~kg} / \mathrm{m}^{3}$ of cement. The shift of peak diameter was commonly observed in all cement contents. Thus, small capillary pore has only marginal impact from freeze and thaw in the total volume. The macropore may reflect the resistance to frost damage in terms of spacing factor [8], which can be defined as average length of connected small pores with voids. Thus, ice formation may largely affect the macro pore wall but the degree of degradation become reduced as capillary pore fraction increases.

3.3. Combined Degradation. As a parametric value of frost damage, the volume of large capillary pore at each cycle was used to relate the migration coefficient as given in Figure 5. 

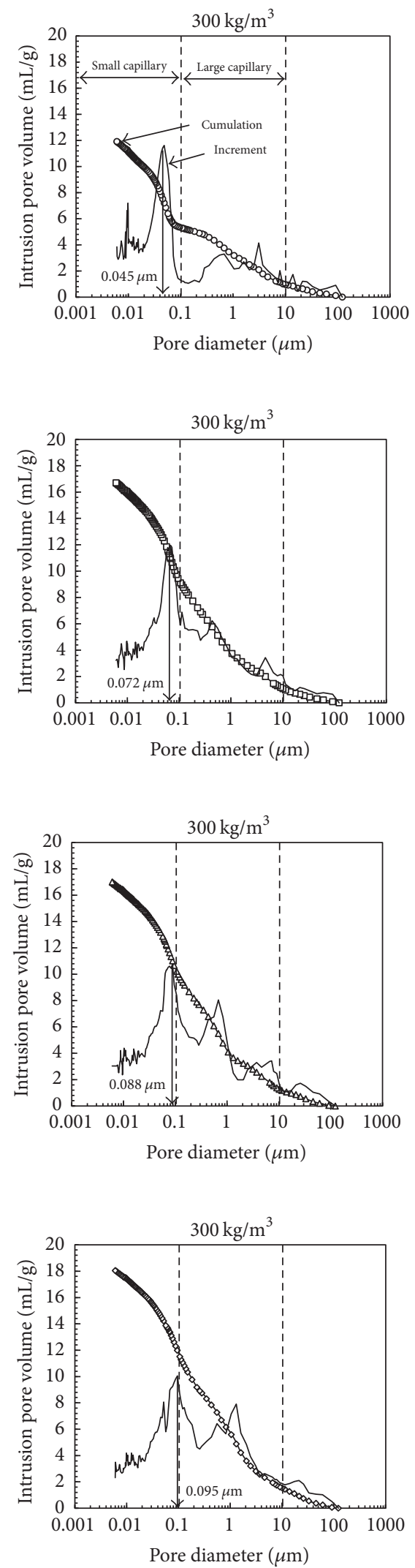

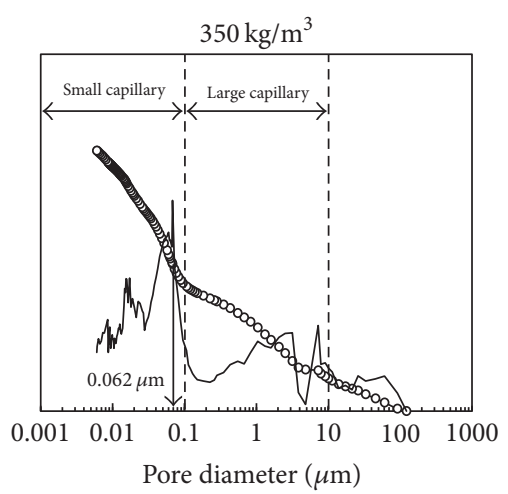

(a)

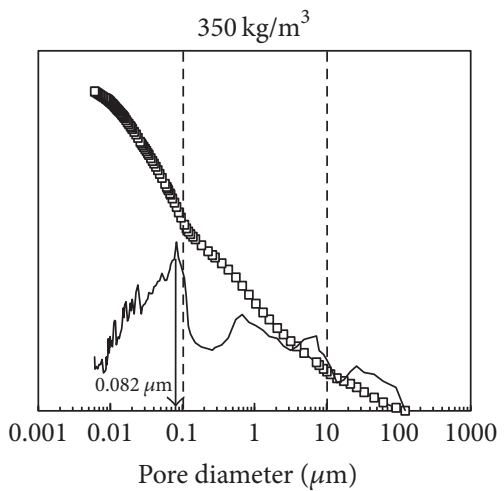

(b)

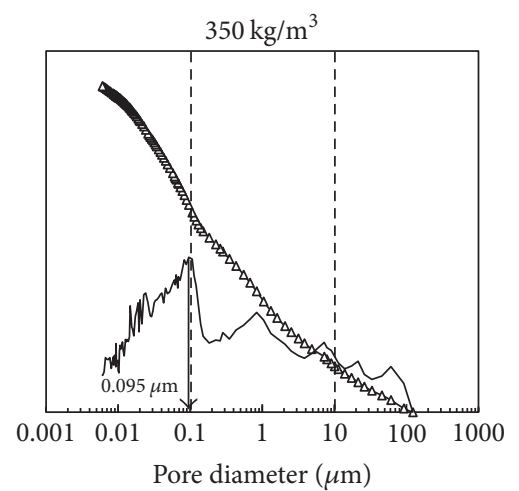

(c)
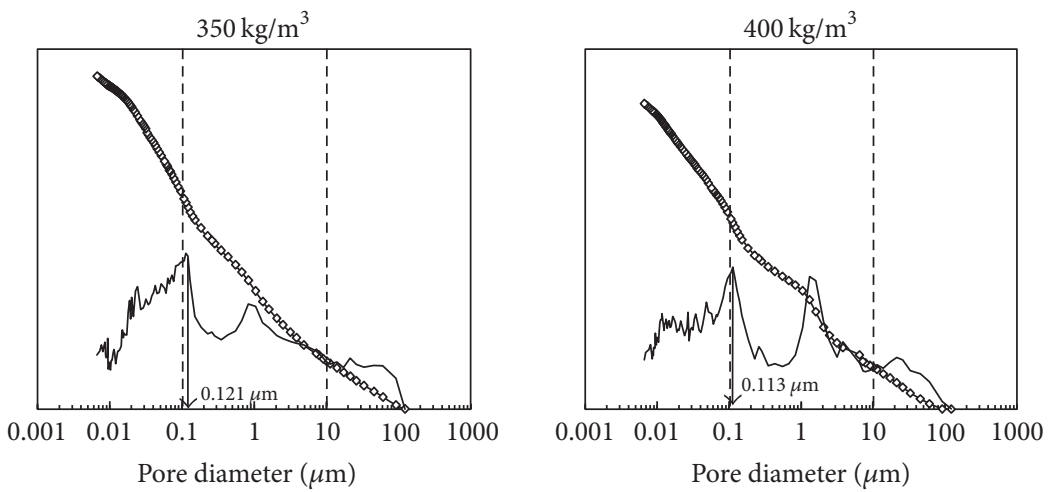

(d)

Figure 4: Pore-size distribution for 300, 350, and $400 \mathrm{~kg} / \mathrm{m}^{3}$ of cement content at (a) 0, (b) 60, (c) 120, and (d) 180 cycles. 


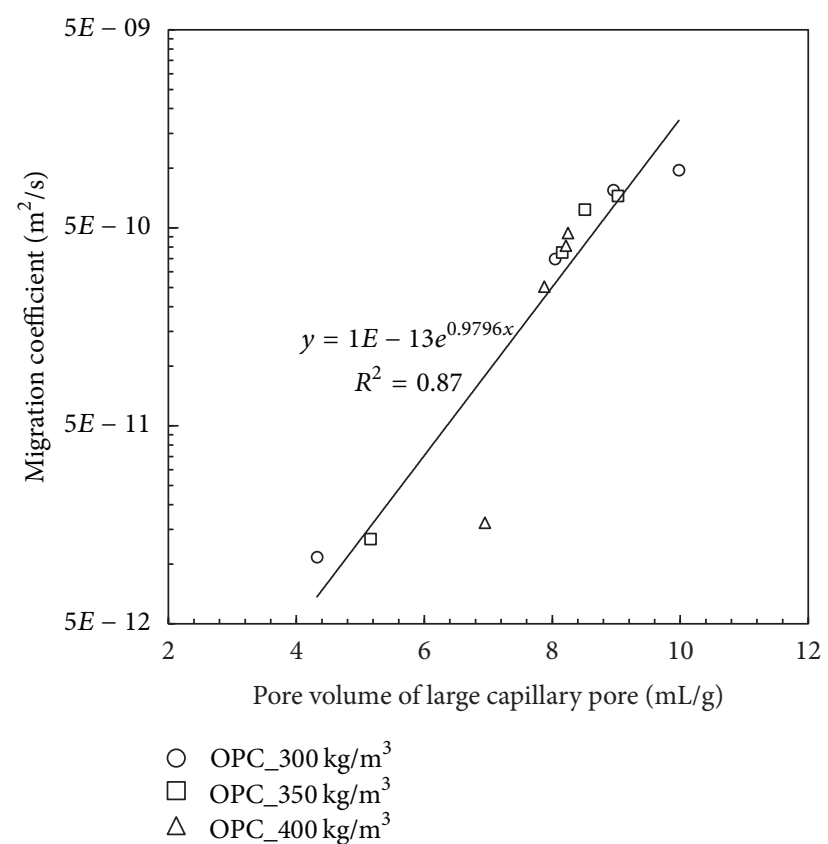

Figure 5: The relation between chloride migration coefficient and pore volume of large capillary pores for three different cement content in the concrete mix at freeze-thaw environment.

It is seen that there was a linear relation between the large capillary pore volume and migration coefficient. It has an important implication in predicting the corrosion risk of concrete under coupling degradation of frost damage and chloride attack. The pore distribution is usually influenced by a free water cement ratio and binder type (i.e., highly grained pozzolanic materials). However, in this study, the pore volume, in particular, large capillary pores, were further generated by the freeze and thaw cyclic condition. Substantially, an increase in the large capillary pores resulted in an increase in the chloride migration. Once a certain level of capillary pores was generated/produced by the freeze and thaw condition, the cement content had a marginal influence on chloride migration. The critical pore is regarded as the smallest pore that can complete the connection of pores to form pore network. Thus, a further formation and generation of pores in terms of increased critical pore diameter during freeze and thaw cycles may increase the penetration of chloride ion. Additionally, the critical pore diameter is crucial on concrete permeability $[9,10]$.

The relation between the chloride migration coefficient and relative dynamic modulus of elasticity was depicted in Figure 6. The relative dynamic modulus of elasticity was strongly influenced by the cement content; an increase in the cement content resulted in an increase in the relative dynamic modulus of elasticity at a given cycle of freeze and thaw. Substantially, a reduction of the relative dynamic modulus of elasticity was accompanied by increased migration of chloride ions. It is evident that the higher cement content concrete imposed the low increasing rate of chloride migration coefficient. Thus, to protect steel from corrosion in concrete, the relative dynamic modulus of elasticity also

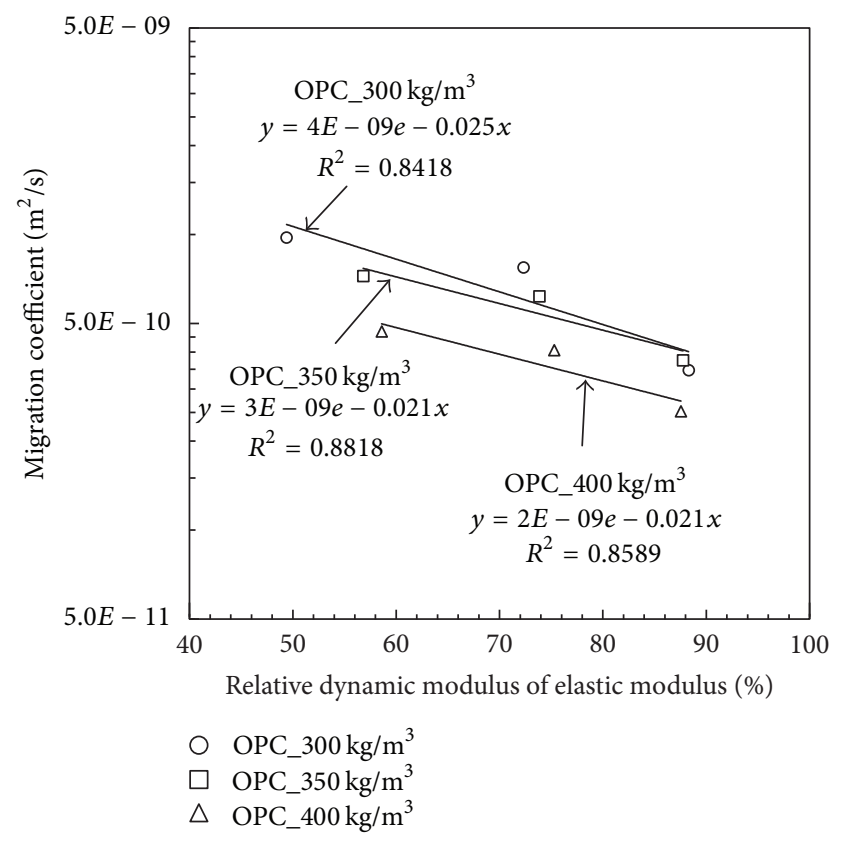

Figure 6: The relation between chloride migration coefficient and relative dynamic modulus of elasticity.

must be kept high against freezing climate, for example, the concrete pavements or bridge deck exposed to the deicing salts in the cold climate. It suggests that the higher cement content could benefit in lowering frost damage and thus mitigating the rate of chloride transport after the frost damage.

\section{Conclusion}

In this study, the coupling degradation of concrete, when exposed to a chloride and frost environment, was assessed by experimental works using OPC. Concrete and mortar specimens were exposed to a cyclic freeze-thaw environment to induce the frost damage, and then the chloride migration and pore structure were examined. The freeze and thaw was repeated up to 180 cycles to meet the quality of concrete specimens for chloride transport. The conclusion obtained from experiments is given as follows:

(1) With no frost damage, the rate of chloride transport in terms of migration was increased by cement content at a given free water cement ratio, which could increase the porosity of the concrete matrix, arising from an increase in the amount of cement paste.

(2) When concrete is subjected to chloride permeation and frost damage, the rate of chloride transport was increased by the number of cycles of freeze and thaw; especially a rapid increase was sighted up to 60 cycles, presumably due to increased large capillary pores produced by microcracking in the cement matrix.

(3) Furthermore, the higher cement content lowered the rate of chloride transport at a given number of cycles of freeze and thaw, since the cement contents increase 
the porosity to resist against frost damage. Substantially, higher cement contents in concrete benefits against the freeze and thaw environment and thus chloride permeation.

\section{Competing Interests}

The authors declare that they have no competing interests.

\section{Acknowledgments}

This research was supported by Basic Science Research Program through the National Research Foundation of Korea (NRF) funded by Ministry of Science, ICT \& Future Planning (no. 2015R1A5A1037548) and a grant (16RDRP-B076268-03) from R\&D program funded by Ministry of Land Infrastructure and Transport of Korea government.

\section{References}

[1] C. L. Page, "Mechanism of corrosion protection in reinforced concrete marine structures," Nature, vol. 258, no. 5535, pp. 514$515,1975$.

[2] K. Y. Ann and H.-W. Song, "Chloride threshold level for corrosion of steel in concrete," Corrosion Science, vol. 49, no. 11, pp. 4113-4133, 2007.

[3] A. M. Neville, Properties of Concrete, Longman Group Ltd, Harlow, UK, 4th edition, 1997.

[4] G. Fagerlund, "On the service life of concrete exposed to frost action," in Freeze-Thaw Durability of Concrete, J. Marchand, M. Pigeon, and M. Setzer, Eds., pp. 23-41, E \& FN Spon, London, UK, 1997.

[5] ASTM C 666, "Standard test method for resistance of concrete to rapid freezing and thawing," ASTM International, 2003.

[6] NT Build 492, "Concrete mortar and cement-based repair materials," Nordtest method, Nordtest, Espoo, Finland, 1999.

[7] B. Zuber and J. Marchand, "Modeling the deterioration of hydrated cement systems exposed to frost action-Part 1: description of the mathematical model," Cement and Concrete Research, vol. 30, no. 12, pp. 1929-1939, 2000.

[8] K. A. Kalliopi, Pore Structure of Cement Based Materials Testing, Interpretation and Requirement, Taylor \& Francis, Oxfordshire, UK, 1st edition, 2006.

[9] L. Cui and J. H. Cahyadi, "Permeability and pore structure of OPC paste," Cement and Concrete Research, vol. 31, no. 2, pp. 277-282, 2001.

[10] P. Halamickova, R. J. Detwiler, D. P. Bentz, and E. J. Garboczi, "Water permeability and chloride ion diffusion in portland cement mortars: relationship to sand content and critical pore diameter," Cement and Concrete Research, vol. 25, no. 4, pp. 790802, 1995. 

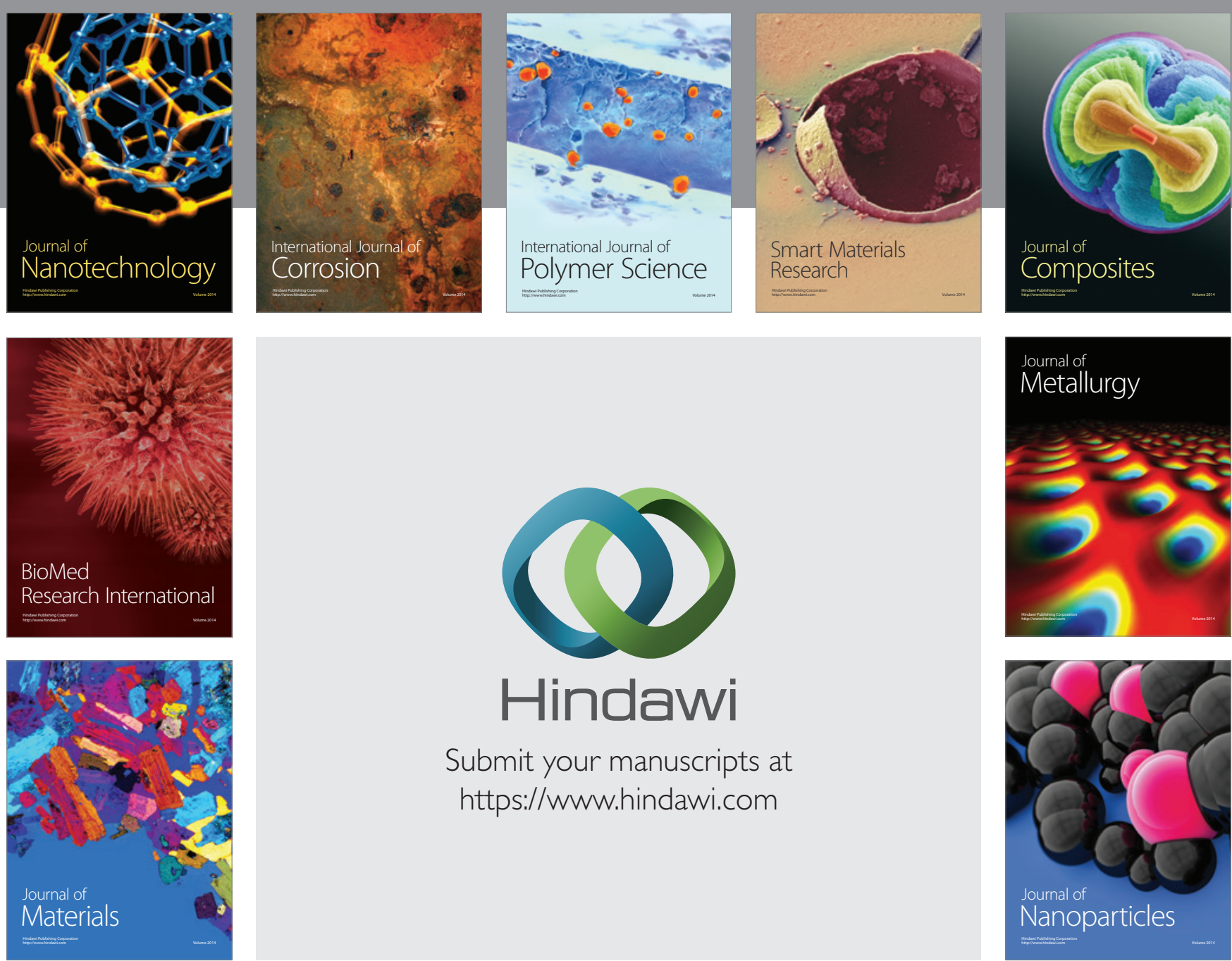

\section{Hindawi}

Submit your manuscripts at

https://www.hindawi.com

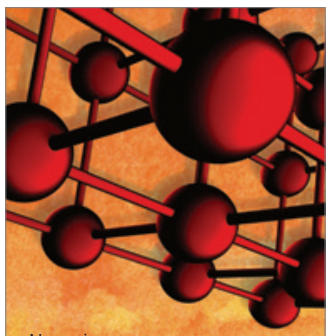

Materials Science and Engineering
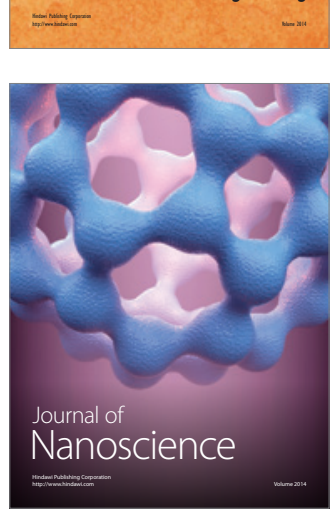
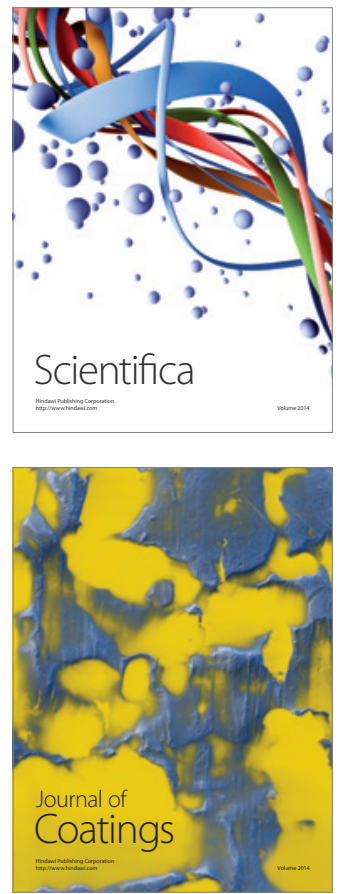
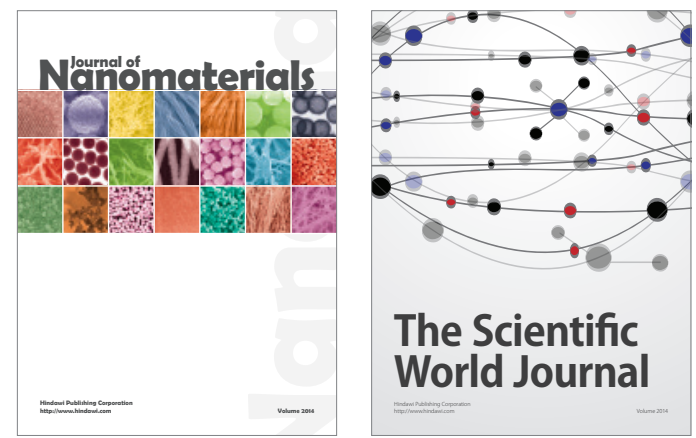

The Scientific World Journal
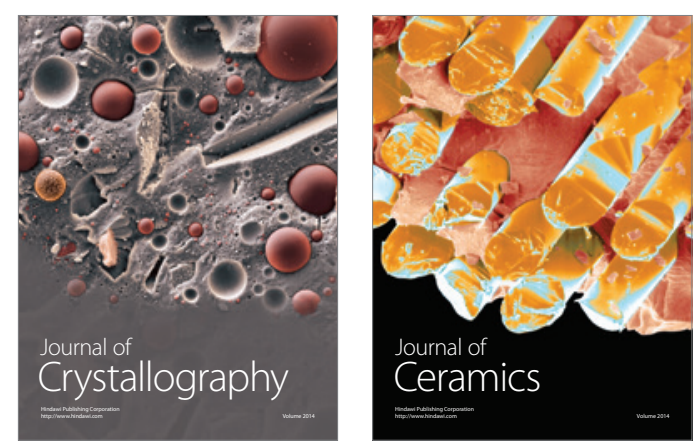
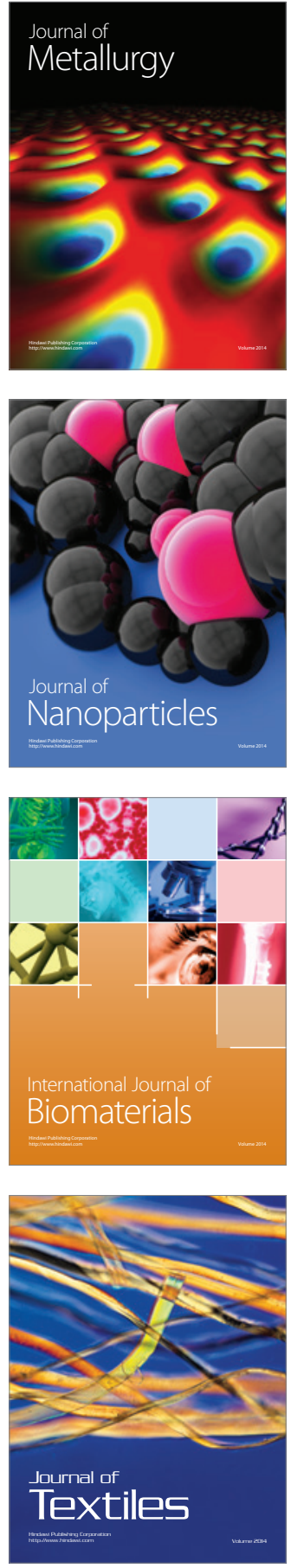